\title{
Impacts of Counselling On People with Special Educational Needs
}

\author{
Beth N. Oluka (Ph.D) ${ }^{1}$ Gloria O. Okorie (Ph.D) ${ }^{2}$ \\ ${ }^{I}$ Dept. of Educational Foundations (Special Education), Ebonyi State University, Nigeria \\ ${ }^{2}$ Federal University, Ndufu-Alike, Ikwo, Ebonyi State, Nigeria
}

\begin{abstract}
People with special educational needs find it very difficult to comply with the demands and expectations of society, possibly because of their perceived lack of performance or potential. They are often treated with little or no interest and sometimes sympathy, with nervousness, fear, embarrassment and/or even disgust. This paper discussed the impacts of counselling on people with special needs as well as the challenges facing them in the society and schools. It also discussed concepts of counselling and stressed that the involvement of counselling with special population therefore is to improve and possibly remedy the challenges, facing people with special needs. The educational challenges facing this category of people are quite obvious and they need new strategies in resolving through counselling. The paper concluded by suggesting that trained personnel in counselling, psychology, social work, pastoral counselling, and psychometric analysis should be placed in the school counselling centres to assist the teachers handle people with special needs and learning disabilities.
\end{abstract}

Keywords: Counselling, People with Special Needs, Learning Disabilities, Special Education

\section{Introduction}

Education for persons with special needs Act (2004) define special educational needs as restriction in capacity of a person to participate in and benefit from education on account of an enduring physical, sensory, mental health or learning disability or any other conduction which results in such individual learning differently from one without that condition. Special educational needs relates to terms like disability, impairment, handicap, and other special needs. UNESCO (2006) refers to people with special needs as those that have emotional, behavioural, sensory, physical or mental disabilities. Students who - for a variety of reasons (intellectual, physical, social, psychological) experience learning disabilities which are more significant than those experienced by majority of learners of the same age. Such students need special educational needs.

According to Olivier and Williams (2005) the mentally handicapped child has special educational needs and is thus often regarded as special in the sense that he requires assistance and support to overcome contextual, social and individual difficulties. These difficulties may also include slow cognitive development (reasoning, problem-solving, remembering and generalizing), as well as slow language development (Gulliford and Upton, 1992). The learner with special educational needs finds it difficult to comply with the demands and expectations of society, possibly because of his perceived lack of performance or potential (Stakes and Hornby, 1997). He is often treated with little interest or sympathy, with uneasiness, fear, embarrassment and/or even disgust. Special needs exist where learners require special help and support if they are to overcome the particular contextual, social and individual disadvantages they face (Donald, Lazarus and Lolwana, 1997). The concept of special needs should include personal and social needs, as well as educational needs (Gulliford and Upton, 1992). Special educational needs require the provision of different or additional resources for children on account of some degree of disability or impairment (Riddell and Brown, 1994).

Egunjobi (2013) also asserts that persons with special educational needs refer to persons with visual auditory, physical impairments, the mentally challenged and the learning disabled. But no matter the disability one has, such individual has constitutional right to education. Olusola (2013) sees persons with special needs as those who have difficulties in realizing their full potential; their emotional, physical, social or intellectual performance falls bellow or rises above that of others. The differences may be related to physical, cognitive, emotional or psycho-social factors or a combination of these. The person with special needs include: those with hearing impairment, gifted and talented, visual, speech and language impairment, orthopaedic impairment, social maladjustment, learning disabilities and multiple impairment (Olusola, 2013). However, these individuals with all forms of special needs require skilled identification; intervention and special care from trained professional special educators to enable them achieve their goals and at the same time receive adequate quality education.

\section{Challenges To People With Special Educational Needs}

People with specific learning disabilities or special educational needs have been segregated from mainstream school practices as well as economic and social activities (Atkinson, Jackson and Walmsley, 1997). Similarly, several people with sensory impairments as well as physical disabilities have been excluded from the 
society (Humphries and Gordon, 1992). At times, isolation of disabled or people with special needs had led to harsh social practices like sterilization and incarceration. Such practices had been observed due to misconceptions of physical and intellectual characteristics (Oliver and Barnes, 1998). The practice of separating the Disabled and people with other forms of special needs from people without disabilities had originated from mistaken notion that human bodies must conform to a certain standard or norm (Wang, 2009).

Wang further asserts that provision of appropriate educational needs for children with special needs or disabilities has long been a common issue in education. Arguments and debates have been raised in line with the right policies on how to educate children with special educational needs. According to Jenkinson (1997), people with disabilities are traditionally educated in segregated classrooms, specifically designed to cater to the students' certain incapacities. Educators find this segregation system beneficial, as they are able to apply curriculum formulated specifically for special people. Likewise, people with special needs benefit from this system not only because of the appropriate curriculum, but also the thought of attending classes with classmates having the same disabilities enhances their confidence or self-esteem as well.

Dunn (1968) in Wang (2009), asserts that the segregation of special children involves many issues of concern, which were generalized into four main points of argument including the students' academic achievement, the detrimental effects of labelling associated with placement outside the mainstream; the racial imbalance in special education, and recent advances in individually paced curricula which would make it possible to accommodate students with disabilities in the regular class. Furthermore, several educators have argued that exposing children into ordinary education settings will be the most effective means of equipping children into better self-supportive adults in the future (Jenkinson, 1997). The students are not the only ones affected by the segregation system. Teachers or educators are also isolated through this kind of setting. Being isolated, their teaching competencies become limited as well. Considering the significance of this point, educators have suggested to integrate the special needs student into normal education settings (Smith, 1998).

\section{Counselling People with Special Needs}

Counselling is viewed as a personalized, intimate interview or dialogue between a person experiencing some emotional, social, educational, physical, and vocational problems and a professional counsellor. It can also be seen as a service that helps individual to solve problems and learn to cope with these problems that are not easy to solve. This is why the special needs population can be focused so that they are assisted out of their needs. Counselling is designed to remove the emotional, psychological and personal social roadblocks placed in the way of an individual by the multidimensional problems of the day to day life.

The involvement of counselling with special population therefore is to improve and possibly remedy the challenges, facing people with special needs. The educational challenges facing this category of people are quite obvious and they need new strategies in resolving through counselling. This is because according to Ipaye (1981), the individual learns new ways if interacting, new ways of obtaining information, new ways of making decisions, and new ways of responding to the environment and new ways of interacting. The task of counselling therefore as seen by Ipaye (1981), Denga (2009), Mallum (1983), Okon (1983), Akinboye (1982) and Bulus (1990) is to give the individual the opportunity to define, explore, discover and adopt ways of living a more satisfying and resourceful life within the social, educational and vocational groupings within which he or she is identified or finds himself or herself. The challenges of life has made some people feeling as not existing well, but through education as a tool for moral, social, economic, political and technological development, has affected some changes in human lives and the society as well (Nweze and Okolie, 2014). Human communities have used education to improve their standard of living, develop new methods and skills of production, so is the need of counselling practices for special need populations.

Counselling has been used to designate a wide range of procedures comprising advice giving, support in times of trouble or need, encouragement, information giving, and test interpretation. Counselling is a process by which a person is assisted to behave in a more rewarding manner. Often times, people with special educational needs are very difficult to handle and teach; the counselling strategies that can be employed for such people or groups should include the following:

a) Confrontation

b) Accurate education

c) Assertiveness training

d) Decision making strategies

e) Peer cluster involvement

The main purpose of this paper is to ascertain the counselling needs for people with special needs. Firstly, students with learning disabilities and special educational needs face myriad of problems that have become increasingly complex including, academic, personal-social, financial, sexual, family and emotional problems. Secondly, there is noticeable absence of information, placement, appraisal, counselling, orientation, 
follow-up and referral services in Nigeria's school system. Thirdly, there are identifiable settings in which the counselling of students with special needs takes place in Nigerian school systems. However, most of them do not utilize the services rendered in these settings. Fourthly, the existing guidance counselling services in Nigeria's secondary schools system are not adequate. Fifthly, the problems facing counselling practices in Nigerian school system include, lack of trained and competent human resources to man the counselling centres, lack of physical facilities and working materials for counselling conveniences.

Since many Nigerian schools do not have formal guidance and counselling centres established for the purpose of meeting counselling needs of students with learning disabilities and special needs (where they are established, they exist only in name), students will not see the necessity for guidance counselling services so as to meet up their counselling needs. Where non-professionals man the counselling centres in schools, the students will not have confidence in them. As such, they will feel that such personnel will not meet their guidance and counselling needs. Therefore, people with special educational needs and other learning disabilities would sometimes prefer to go to their parents or friends for their counselling needs who lack expert knowledge (Nweze and Okolie, 2014). The implication here is that the problems they required assistance remain largely unresolved. The largely unresolved problems result in social and psychological inadequacies, which express themselves in riotous behaviours.

The establishment of guidance and counselling centres in Nigerian schools and employing professionally trained counsellors to man the centres would relieve parents and school the problems of managing students with special needs and learning disabilities. The establishment of fully functional counselling centres has implication of producing better-adjusted students who will find themselves more useful to the society despite their disabilities and special needs. Experts are to be properly trained to man counselling centres in Nigerian schools.

For a more effective counselling services delivery to students, certain activities should be undertaken. A vigorous enlightenment of students' programme should be mounted to sensitise them on the need to seek counselling intervention whenever they have problems that weigh them down. The special educators should also be trained to work closely with professional counsellors such that whenever the need to manage the disabled and special needs arises, it would be very easy to handle such situation. School authorities should allocate offices where there are no existing ones (and more offices in addition to the existing ones where existing ones are inadequate), to be used as counselling rooms for students with special educational needs. The counselling centre should be properly equipped with the following; furniture for administrative and counselling conveniences; file cabinet for record keeping, notice boards for information dissemination; log book; advertisement forms to enlighten students on services in the counselling centre, files; counselling record; registration form; request form for counselling interview, case report sheet, consultation forms, and appointment slip (Nweze and Okolie, 2014).

\section{Conclusion}

Since proper rendering of counselling services is dependent on adequate provision of experts, physical facilities and working materials, Nigerian school authorities should ensure that the personnel who deliver most of these services are experts in their fields. Trained personnel in counselling, psychology, social work, pastoral counselling, and psychometric analysis should be placed in the school counselling centres. Trained personnel with working experience should equally be placed in suitable positions where basic student services are rendered, such as medical, information, orientation, counselling, and admission services. These counselling experts who would be handling the students with special needs should be supervised from time to time to guarantee that their duties are properly discharged. Also, in order to equip school counselling centres with physical facilities and working materials essential for delivery of counselling services, Nigerian school authorities should augment funds for assistance in provision of facilities and materials from non governmental bodies, philanthropists and private agencies. Since the government is the major source of finance to schools in Nigeria, it is advised to increase its fund allocations to the schools to enable them provide suggested guidance services. The government should equally set up a monitoring team, tasked with function of carrying out routine checks on expenditure pattern of the school of which, counselling is one. Following the dearth of qualified personnel to work in the counselling centres, and shortage of fund to employ more hands, a teamwork approach to counselling is hereby recommended. In teamwork approach, special education teachers, counsellors, nurses, psychologists and specialists in various areas should exchange information and understanding about the student, which result from their special professional knowledge, skill, points of view and competencies. Here, all available data are amassed, perceived causes of the problem are highlighted, and group decisions are made regarding the most effective treatment to be employed. 


\section{References}

[1]. Atkinson, D., Jackson, M. and Walmsley, J. (1997) Forgotten Lives: Exploring the History of Learning Disability. Kidderminster: BILD

[2]. Akinboye, J.O. (1982). Guidance and Counselling: Strategies and Youth Development. Ibadan: University Press.

[3]. Bulus, I. (1990) Guidance Practice in School, Jos: Ehindero Press.

[4]. Egunjobi, R. A. (2013). Virtual Library for persons with Special Education Needs (ed)

[5]. Denga, D.I. (2009). Orientating Nigerians towards Functional Societal Collaboration and partnerships for achieving the Goals of the Seven Point Agenda: The Guidance and Counselling Perspective. Maiden Distinguished annual lecture of CASSON. Peak Press Ltd.

[6]. Donald, D., Lazarus, S. and Lolwana, P. (1997). Educational psychology in social context. Challenges of developing social issues and special needs in South Africa. Cape Town: Oxford University Press.

[7]. Dunn, L M. (1968). Special education for the mildly retarded: Is much of it justifiable? Exceptional Children, $35,5-22$.

[8]. Gulliford, R. and Upton, G. (1992). Special educational needs. London: Routledge.

[9]. Humphries, S. and Gordon, P. (1993). Out of Sight: The Experience of Disability 1900-1950. Plymouth: Northcote House.

[10]. Jenkinson, J.C. (1997) Mainstream or Special? Educating Students with Disabilities. London: Routledge.

[11]. Mallum, M.P. (1983). Understanding Basic Principles to Guidance Services in Nigeria, Jos: University Press.

[12]. Nweze, T. and Okolie, U. C. (2014). Assessment of Relationships between Students' Counselling Needs, Class Levels and Locations: A Benue State Technical Colleges Study. Journal of Educational Policy and Entrepreneurial Research (1) 2. $262-276$.

[13]. Oliver, M. and Barnes, C. (1998). Disabled People and Social Policy: From Exclusion to Inclusion. London: Longman.

[14]. Olusola, O. (2013). Legislation and Litigation for Special Needs Persons in Nigeria (ed)

[15]. Riddell, S. and Brown, S. (1994). Special educational needs policy in the 1990's. London and New York: Routledge.

[16]. Smith, C. R. (1998). Learning disabilities: the interaction of learner, task, and setting. Boston, Allyn and Bacon.

[17]. Stakes, R. and Hornby, G. (1997). Change in special education. London: Cassell.

[18]. UNESCO (2006). ICTs in Education for People with Special Needs Specialized Training Course. Available at http:ru.iite.unesco.org

[19]. Wang, H. L. (2009). Should All Students with Special Educational Needs (SEN) Be Included in Mainstream Education Provision? A Critical Analysis. International Education Studies. 